\title{
Tapentadol and Oxycodone/Naloxone Prescribing Patterns in Primary Health Care in Catalonia, Spain: A Cross-Sectional Study
}

\author{
Montserrat Viñas-Bastart ${ }^{\prime}$ \\ Míriam Oms-Arias ${ }^{2}$ \\ Àfrica Pedraza-Gutiérrez ${ }^{2}$ \\ Irene Lizano-Díez (D) \\ Eduardo L Mariño (D) \\ Pilar Modamio (D) \\ 'Clinical Pharmacy and Pharmaceutical \\ Care Unit, Department of Pharmacy and \\ Pharmaceutical Technology, and Physical \\ Chemistry, Faculty of Pharmacy and Food \\ Sciences, University of Barcelona, \\ Barcelona, Spain; ${ }^{2}$ Costa de Ponent \\ Primary Care Directorate, Catalan \\ Institute of Health, L'Hospitalet de \\ Llobregat, Barcelona, Spain
}

Correspondence: Pilar Modamio Clinical Pharmacy and Pharmaceutical Care Unit, Department of Pharmacy and Pharmaceutical Technology, and Physical Chemistry, Faculty of Pharmacy and Food Sciences, University of Barcelona, Av. Joan XXIII, 27-3I, Barcelona, 08028, Spain $\mathrm{Tel} / \mathrm{Fax}+34934024544$

Email pmodamio@ub.edu
Objective: To characterize the use of tapentadol and the combination oxycodone/naloxone in primary health care. Data on their use and possible misuse will allow the identification of risk factors and to design protocols to reduce and prevent avoidable harm to patients being treated for pain.

Design: A descriptive, cross-sectional and multicenter study was performed.

Setting: Fifty-three primary health care teams, which provides healthcare for $1,300,000$ inhabitants.

Patients: A total of 1840 patients had active prescriptions of tapentadol and 985 of oxycodone/naloxone.

Methods: Demographic (age, sex) and clinical (glomerular filtration rate; active liver disease; dosing and duration of treatment), prescribed daily dose (according to age, sex, length of treatment), concomitant analgesic treatment and diagnosis. Patient information was obtained from medical records.

Results: Most of the patients were women ( $>74.0 \%$ in both cases), and the average age was 69.3 years (women: $70.1 \pm 13.2$; men: $66.7 \pm 13.9$ years) in the case of tapentadol and 70.6 years (women: $64.0 \pm 13.6$; men: $72.6 \pm 14.3$ years) in the case of oxycodone/naloxone. Only $12.2 \%$ of patients taking tapentadol and $12.1 \%$ taking oxycodone/naloxone had a normal renal function. In both cases, $4.1 \%$ of patients had active liver disease. The average length of treatment was 246.4 days in oxycodone/naloxone and 199.0 days in tapentadol. It was recorded that $85.1 \%$ of patients in the case of tapentadol and $89.0 \%$ in the oxycodone/ naloxone had at least another drug prescribed for pain. About $42.2 \%$ of patients treated with tapentadol and $34.4 \%$ of patients treated with oxycodone/naloxone had associated neuralgia as a diagnosis.

Conclusion: The pattern of use and profile of patients with tapentadol and oxycodone/ naloxone had more similarities than differences, and suggested that prescribing practice, and monitoring should be assessed regularly to ensure patient safety and effective management of pain.

Keywords: clinical practice pattern, chronic pain, opioids, oxycodone/naloxone, primary health care, culture, tapentadol

\section{Introduction}

Although there is no uniformity in terms of its definition, chronic pain is generally understood as the one that persists beyond 3 or 6 months from its appearance or beyond the expected healing period for a given lesion. ${ }^{1}$ Chronic pain is one of the most frequent causes why general population looks for medical treatment, and is 
often poorly managed. ${ }^{2,3}$ Approximately $20 \%$ of United States adults have chronic pain ${ }^{4}$ and it also affects $20 \%$ of European citizens. ${ }^{5}$ Spain shows a prevalence of chronic pain in the adult population ( $\geq 18$ years) of $16.6 \%{ }^{6}$

Chronic opioid therapy has limited data supporting its long-term effectiveness more than three months for the management of chronic non-malignant pain ${ }^{7}$ and the use in the long term remains controversial, also because of the adverse events. ${ }^{8}$ Besides, it must be taken into account that chronic pain is often accompanied by mood and sleep disorders, and other chronic conditions that can result in complex medication regimens and an increased risk of drug interactions and side effects. ${ }^{7}$

Regarding opioids' side effects, the most habitual encompass dry mouth, vomiting, nausea, fatigue, increased sweating, itching, drowsiness and constipation, with a remarkable negative impact on patient quality of life. ${ }^{8,9}$ Tapentadol demonstrated to have fewer side effects at the central nervous system (CNS), which could reduce dependence $^{10,11}$ and fewer gastrointestinal side effects than morphine and oxycodone. ${ }^{12}$ In this regard, the combination of naloxone with oxycodone improves opioidinduced bowel dysfunction, characterized by constipation, incomplete evacuation, bloating, and increased gastric reflux, which helps increase the acceptability of opioid treatment for pain. ${ }^{13,14}$

In Spain, tapentadol is still covered by patent law and dosage forms are only marketed as trademarks, both the extended-release tablets (dosages of 25, 50, 100, 150, 200 and $250 \mathrm{mg}$ ) and the immediate-release tablets (dosages of 50,75 and $100 \mathrm{mg}$ ). ${ }^{15}$ Oxycodone/naloxone combination is marketed as trademarks and generics of extendedrelease tablets in different dosages $(5 / 2.5 \mathrm{mg}, 10 / 5 \mathrm{mg}$, 20/10 mg and 40/20 mg). ${ }^{16}$ An increase in the consumption of tapentadol and oxycodone/naloxone expressed in defined daily doses per 1000 inhabitants per day (DHD) over the years 2014 to 2017 (1.3\% DHD tapentadol and $1.4 \%$ DHD oxycodone/naloxone to $2.3 \%$ DHD and $1.9 \%$ DHD, respectively) was found in our study area of primary health care. Despite the increasing influence of general practitioners on the opioid analgesics' prescription for the chronic pain treatment, to our knowledge, there were no findings in the literature of descriptive studies and comparative analysis of the use of these drugs in primary care practice. ${ }^{8}$ Thus, the aim of the present study was to characterize the use of tapentadol and the combination oxycodone/naloxone in primary health care. Data on their use and possible misuse will allow the identification of risk factors and to design protocols to reduce and prevent avoidable harm to patients being treated for pain.

\section{Materials and Methods Design and Setting of the Study}

A descriptive and cross-sectional multicenter study was carried out. It covered fifty-three primary health care teams in the Primary Care Directorate (DAP) Costa de Ponent of the Catalan Institute of Health (ICS), which provides healthcare for 1.3 million inhabitants. ${ }^{17,18}$

\section{Data Source, Collection, and Variables}

The target population were patients with an active prescription of tapentadol or the oxycodone/naloxone combination on August 13, 2018. The Summary of Product Characteristics (SmPC) of all (brand-named and generic) marketed prescription medicines containing these drugs were reviewed to evaluate their authorized therapeutic use. The information of the patients was obtained and extracted anonymously.

The variables studied about patient data were age, sex, glomerular filtration rate (GFR: $>90 \mathrm{~mL} / \mathrm{min}, 60-89 \mathrm{~mL} /$ min, $45-59 \mathrm{~mL} / \mathrm{min}, 30-44 \mathrm{~mL} / \mathrm{min}, 15-29 \mathrm{~mL} / \mathrm{min}$ and data not registered) and active liver disease. As for the prescription data: duration of treatment ( $>30$ days, 31-90 days, 91-180 days, 181-366 days, 1-2 years, and more than 2 years), prescribed daily dose according to age (in case of oxycodone/naloxone doses are only referred to as oxycodone since the dose of naloxone is always half of oxycodone), sex and length of treatment, concomitant analgesic treatment and diagnosis. Patient data was obtained from clinical records (e-CAP computer program), whereas diagnoses were defined according to the International Classification of Diseases (ICD-10). The computer program used (e-CAP) contains patients' demographic data, clinical history, diseases, drugs, treatment plans, vaccinations, allergies, radiology images, analytical and test results, therapeutic procedures, hospital discharge dates, and visits to hospital emergency. ${ }^{17}$

Regarding the ICS, it is the main provider of public health services in Catalonia, Spain. It is a leading provider in its three basic areas of activity: healthcare (its main area), research and teaching. The ICS provides health services to $83 \%$ of all Catalan citizens (over 5.5 million people). ${ }^{18}$ It is comprised of 8 hospitals and 287 primary care teams, located throughout the entire Catalan territory. The primary care teams are made up of a varying 
number of professionals (general practitioners, pediatricians, nurses, auxiliary nurses, dental surgeons, social workers, and administrative staff) and are responsible for providing free primary healthcare to the population that lives within their catchment area. The management structures or DAPs are directly responsible for all the health centers, services, and institutions within their corresponding area. Concretely, DAP Costa de Ponent directly manages primary health care services in the southern Barcelona Metropolitan Area (Catalonia, Spain). ${ }^{18}$

\section{Ethical Review Board Approval}

Given that the extraction of information was carried out anonymously and the relationship was not available to recover which real cases the information corresponds to, it was not necessary to ask for the informed consent of the patients studied or institutional review board approval, in accordance with Spanish regulations prior to January 2, 2021 (Order SAS/3470/2009, of December 16, which publishes the guidelines on post-authorization studies of an observational type for medicines for human use and Chapter VI of Royal Decree 577/2013, of July 26, which regulates pharmacovigilance of medicinal products for human use).

\section{Data Analysis}

Discrete variables were expressed in proportions or frequencies, and continuous variables as means and standard deviations, and it was assumed that the data were normally distributed. Frequencies were compared in a bivariate analysis using $\chi$ square and means using Student's $t$ test or analysis of variance. As a post hoc test was used Bonferroni. Pearson's correlation was used in the relationship of two quantitative variables. A p-value $\leq 0.05$ was considered statistically significant. The data were analyzed using SPSS software, version 17.0.

\section{Results \\ Description of the Population}

At the time of the study (13 August 2018), 1840 patients had active prescription of tapentadol and 985 patients of the combination oxycodone/naloxone. In the case of tapentadol, all patients were prescribed extended-release tablets and $0.3 \%(\mathrm{~N}=6)$ of them had also oxycodone/naloxone at the same time. As for oxycodone/naloxone, $0.6 \%(\mathrm{~N}=6)$ of patients had also tapentadol at the same time.
The $74.8 \%(\mathrm{~N}=1377)$ of patients with active prescription of tapentadol extended release and $74.1 \%(\mathrm{~N}=729)$ of patients in the case of oxycodone/naloxone were women. No statistical differences were found in terms of sex between patients taking tapentadol and those taking oxycodone/naloxone. Regarding patients' age, the average was 69.3 years (women: $70.1 \pm 13.2$ years, male: $66.7 \pm 13.9$ years) in the case of tapentadol and 70.6 years (women: $64.0 \pm 13.6$ years; male: $72.6 \pm 14.3$ years) in oxycodone/ naloxone. The age of women who took tapentadol was slightly higher but statistically significant than those who took oxycodone. The distribution of patients by age is shown in Figure 1A.

\section{Renal and Hepatic Function}

As for the renal function, in the case of tapentadol, 12.2\% of patients $(\mathrm{N}=225)$ had a normal renal function (GFR $>$ $90 \mathrm{~mL} / \mathrm{min}$ ) and in the case of oxycodone/naloxone, $12.1 \%(\mathrm{~N}=119)$. Figure 1B shows the distribution of patients depending on the GFR value registered to determine the stage of kidney disease. In addition, it was found that around $5 \%$ of patients $(5.6 \%, \mathrm{~N}=104$ in case of tapentadol and $4.8 \%, \mathrm{~N}=47$ in case of oxycodone/naloxone) had no data recorded for their renal function.

Regarding liver function, $4.1 \%$ of patients with tapentadol $(\mathrm{N}=75)$ had active liver disease. Liver disease includes hepatitis $\mathrm{C}$ virus, hepatitis $\mathrm{B}$ virus, alcoholic and non-alcoholic fatty liver disease, autoimmune hepatitis, cholestasis/diseases of the biliary tract, hepatotoxicity for medicines or herbal supplements, and hepatotoxicity leading to cirrhosis. In the case of oxycodone/naloxone, $4.1 \%$ of patients $(\mathrm{N}=40)$ had active liver disease.

There was no found co-prescription of the two drugs in patients with impaired renal or hepatic function.

\section{Treatment Duration}

The duration of treatment with extended release tapentadol and oxycodone/naloxone is ranged from less than one month to more than 2 years (Figure 1C). Oxycodone/naloxone treatments had a longer duration than tapentadol treatments (246.4 \pm 283.8 days vs.199.0 \pm 219.7 days, respectively) and this difference was statistically significant $(p<0.005)$.

\section{Prescribed Daily Dose}

The average daily dose prescribed to patients treated with extended-release tablets of tapentadol and patients treated with oxycodone/naloxone was, respectively, $112.3 \pm 87 \mathrm{mg}$ (range: $6.1 \mathrm{mg}$ - $1000 \mathrm{mg}$ ) and 23.5 $\pm 20.6 \mathrm{mg}$ of 


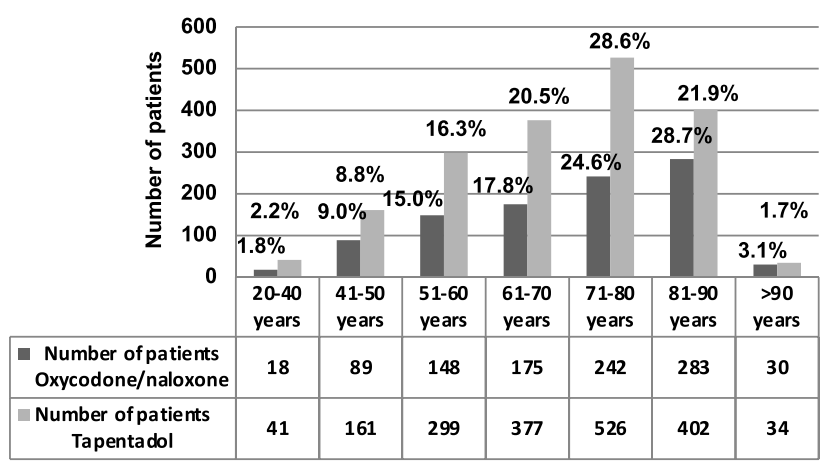

A

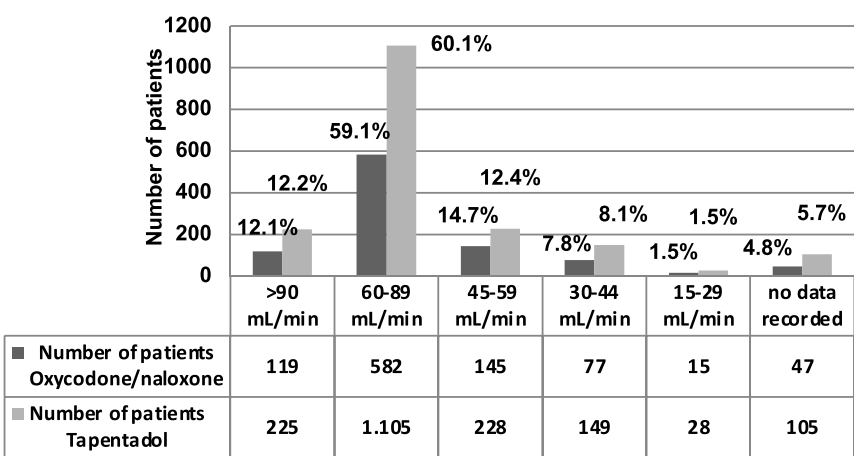

B

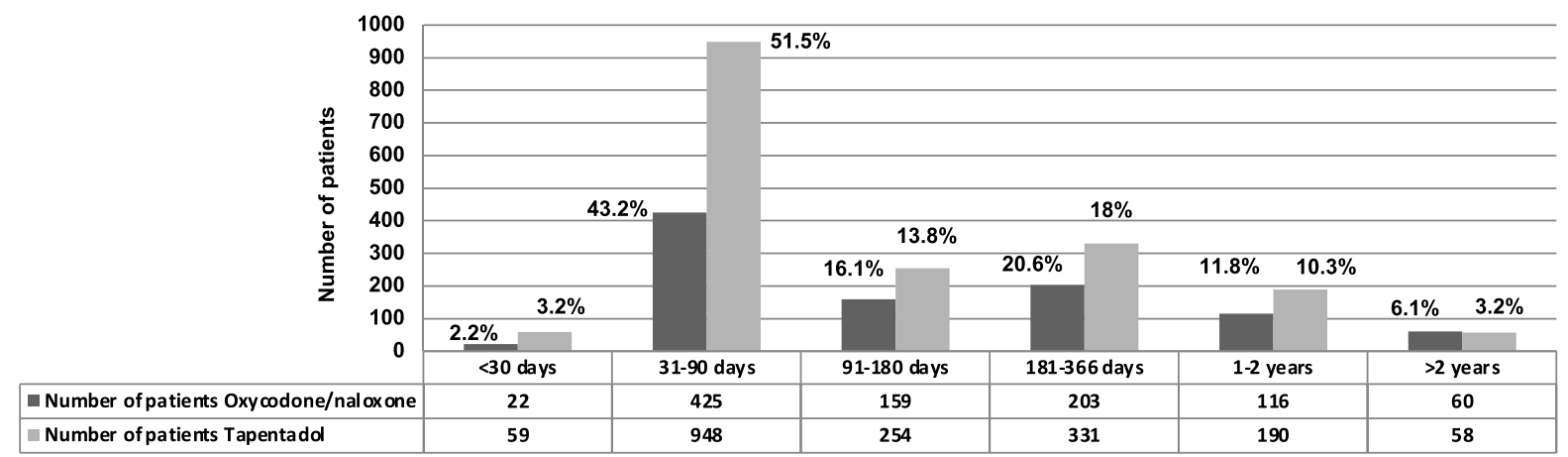

C

Figure I Distribution of patients by age (A), by Glomerular Filtration Rate (B), and by duration of treatment (C) with tapentadol vs oxycodone/naloxone.

oxycodone (range: $1.2 \mathrm{mg}-160 \mathrm{mg}$ ). We found, in the case of tapentadol, 146 patients $(7.4 \%)$ with doses below $50 \mathrm{mg} /$ day (underdosed) and above $500 \mathrm{mg} /$ day (overdosed). In oxycodone/naloxone, we found 179 patients (18.2\%) with doses lower than the recommended 10/5 every $12 \mathrm{~h}$. The daily dose was calculated according to frequency and dosage, finding frequencies of 1 every 99 h. Figure $2 \mathrm{~A}$ shows the average daily dose established according to age groups. In the case of tapentadol, the highest daily dose was in the age group of 41-50 years (average $123.2 \pm 109.3 \mathrm{mg}$ ), although there were no significant differences in the daily dose in any of the age ranges established $(p=0.065)$. In general, younger patients (range: 20-40 years) were taking lower doses of tapentadol, however, three of those patients were taking more than the authorized dose (500 mg according to the SmPC).

With respect to the oxycodone/naloxone, the highest daily dose was in the age group between 20 and 40 years (average of $36.2 \pm 35.2 \mathrm{mg}$ of oxycodone). The oldest patients (range: 81 - >91 years) were taking the lowest doses and no patient were taking more than the authorized dose (160 mg of oxycodone/80 $\mathrm{mg}$ of naloxone according to the SmPC). There were statistically significant agerelated differences in the average daily dose of oxycodone $(\mathrm{p}<0.005)$.

Furthermore, there appeared to be a negative significant correlation between age and average daily dose in patients taking oxycodone/naloxone $(\mathrm{r}=-0.173$; $\mathrm{p}<$ 0.005).

On the other hand, the average daily dose used was lower in women than men in both medicines (Figure 2B). In the case of oxycodone, the dose in men $(26.8 \pm 25.7 \mathrm{mg})$ was statistically significant higher $(p=0.012)$ than that of women $(22.4 \pm 18.3 \mathrm{mg})$.

When analyzing both the average daily dose data of the drugs and the duration of treatment (Figure 2C), patients treated with the lowest daily dose of tapentadol had the shortest duration of treatment. In addition, there appeared to be a significant positive correlation between the two variables $(r=0.097 ; p<0.005)$. In the case of oxycodone/ naloxone, patients with treatment length between one and two years were the ones with the highest average daily dose. In this sense, a significant correlation between the two variables was found $(r=0.073 ; p=0.022)$. 


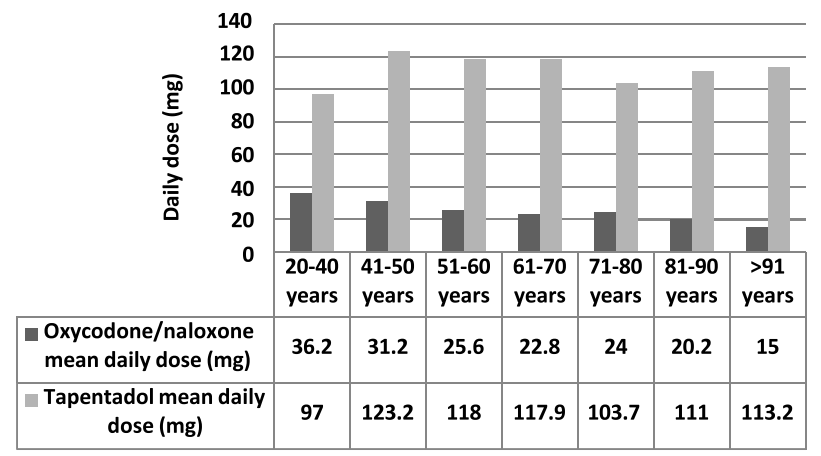

A

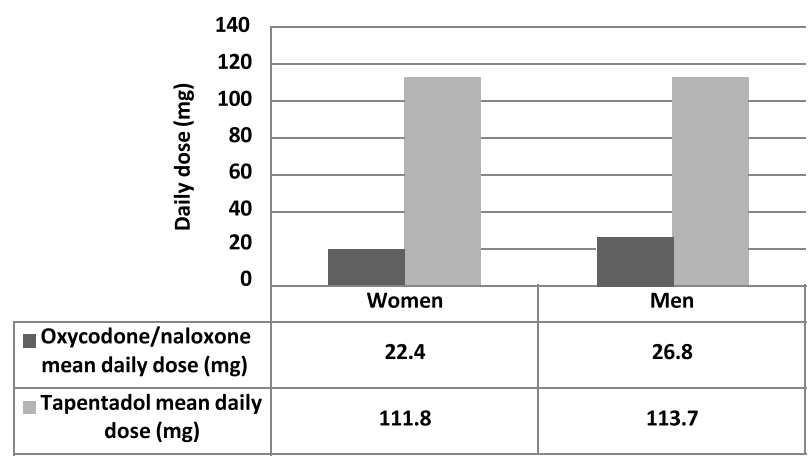

B

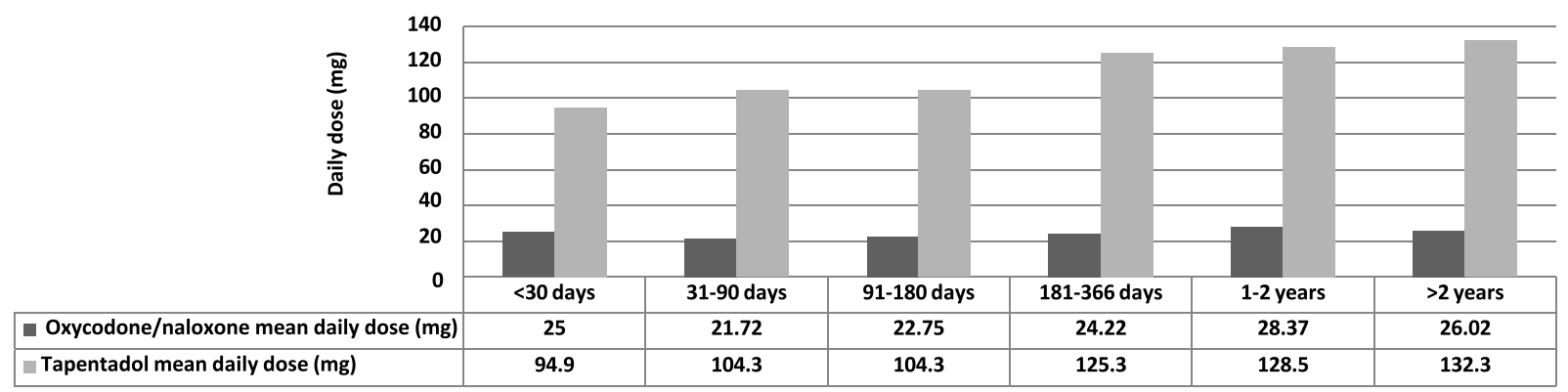

\section{C}

Figure 2 Average daily dose according to age groups (A), to sex (B), and to duration of treatment (C).

\section{Drug Treatment Combination with Tapentadol and Oxycodone/Naloxone}

These drugs were also prescribed along with additional pain drugs, such as, NSAIDs, antiepilectics such as pregabalin, other non-opioid analgesics such as metamizole, anxiolytics and hypnotics, selective inhibitors of serotonin reuptake inhibitors (SSRIs), antiepileptics such us gabapentin, sedatives, tricyclic antidepressants (TCAs) and other opioid analgesics. Besides, patients could be taking simultaneously more than one medication (Figure 3). Therefore, in the case of tapentadol, it was recorded that $85.1 \%(\mathrm{~N}=1566)$ of patients had at least another drug prescribed for pain. Mainly, 56.0\% $(\mathrm{N}=1030)$ of patients had a concomitant acetaminophen, $21.4 \%(\mathrm{~N}=393)$ pregabalin, 21.1\% ( $\mathrm{N}=388)$ metamizole, $11.6 \%(\mathrm{~N}=214)$ diazepam, 7.1\% $(\mathrm{N}=196)$ duloxetine and 10.5\% $(\mathrm{N}=$ 193) gabapentin. As for oxycodone/naloxone, $89.0 \%$ of patients $(\mathrm{N}=877)$ had at least another drug prescribed for pain. Predominantly, $60.1 \%(\mathrm{~N}=592)$ of patients had concomitant acetaminophen, $23.7 \%(\mathrm{~N}=233)$ pregabalin,
$21.8 \%(\mathrm{~N}=215)$ metamizole, $13.0 \%(\mathrm{~N}=128)$ diazepam, $11.3 \%(\mathrm{~N}=111)$ gabapentin and $11.2 \%(\mathrm{~N}=110)$ duloxetine. Patients with oxycodone/naloxone treatment took more adjuvant drugs $(1.9 \pm 1.2$ drugs $)$ than patients with tapentadol treatment $(1.7 \pm 1.2$ drugs $)$ and this difference was statistically significant $(\mathrm{p}=0.005)$.

\section{Diagnoses}

The study found that $42.2 \%$ of patients treated with tapentadol $(\mathrm{N}=776)$ had neuralgia as a diagnosis, $14.4 \%$ of patients $(\mathrm{N}=265)$ osteoarthritis, $7.8 \%(\mathrm{~N}=144)$ had more than one diagnosis of pain, 5.3\% $(\mathrm{N}=97)$ neoplasic processes, $5.3 \%(\mathrm{~N}=94)$ fracture and osteoporosis, $4.7 \%$ $(\mathrm{N}=86)$ fibromyalgia, and 4.3\% $(\mathrm{N}=76)$ did not have a diagnosis (Table 1). There were $0.43 \%$ of patients $(\mathrm{N}$ $=8$ ) with an incorrect indication including depressive disorder $(\mathrm{N}=4)$ and diabetes mellitus $(\mathrm{N}=4)$.

In the case of treatment with oxycodone/naloxone, $34.0 \%$ of patients $(\mathrm{N}=335)$ had neuralgia as a diagnosis, lumbago with sciatica, sciatica, and spondylosis, $15.8 \%(\mathrm{~N}=156)$ intervertebral disc disorders, $13.6 \%$ 


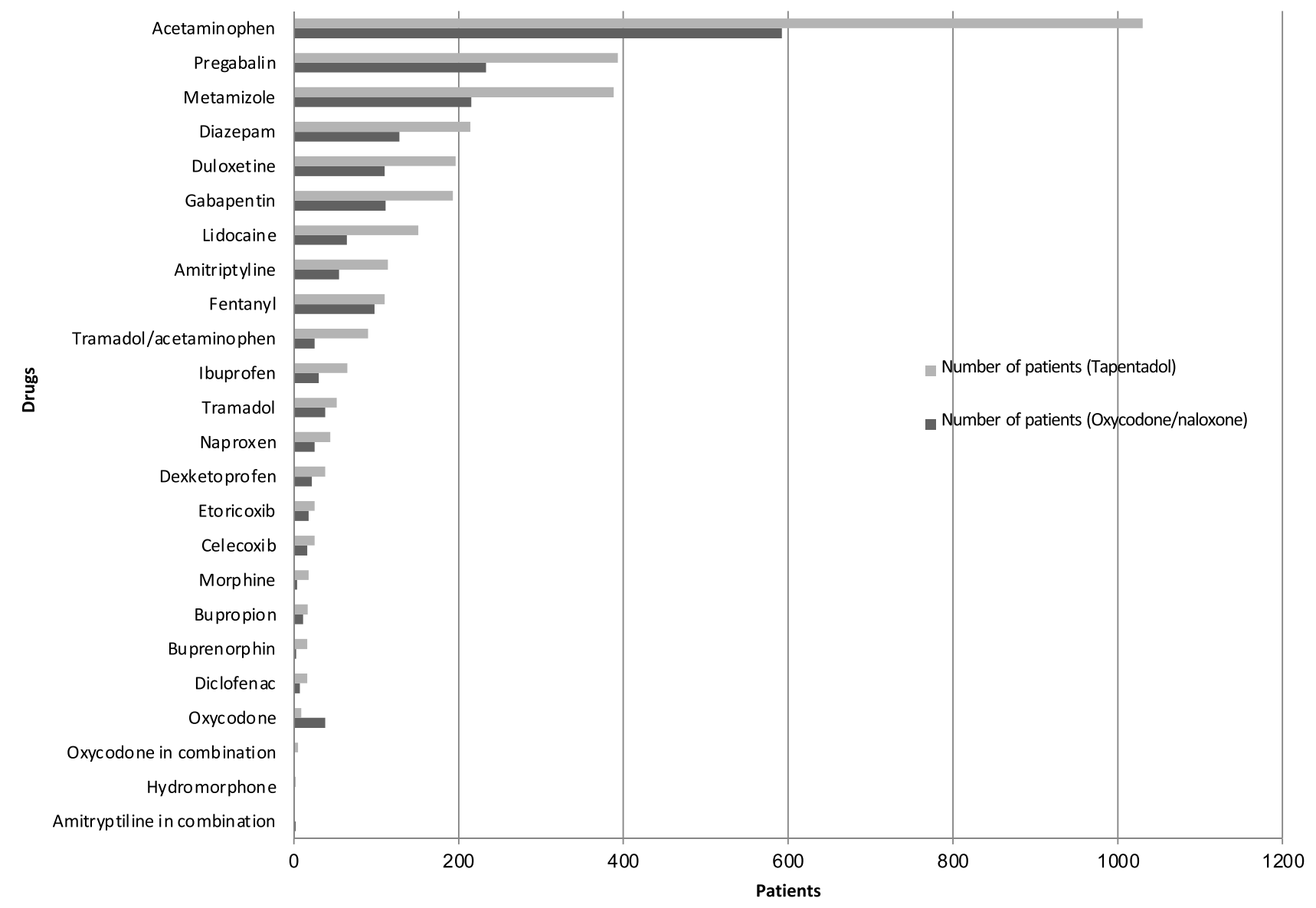

Figure 3 Distribution of drug treatment combination and number of patients.

$(\mathrm{N}=134)$ osteoarthritis, $12.4 \%(\mathrm{~N}=122)$ had more than one diagnosis of pain, $7.9 \%(\mathrm{~N}=78)$ fracture and osteoporosis, $5.1 \%(\mathrm{~N}=50)$ neoplasic processes and $(\mathrm{N}=50)$ chronic pain, $4.9 \%(\mathrm{~N}=48)$ fibromyalgia and $4 \%(\mathrm{~N}=39)$ did not have a diagnosis (Table 1 ).

On the other hand, $5.1 \%(\mathrm{~N}=93)$ and $6.5 \%(\mathrm{~N}=64)$ of patients had other diagnoses, respectively (Tables 1-3).

\section{Diagnoses vs Daily Dose}

In the case of tapentadol, the highest daily dose was in the incorrect indications of depressive disorder and diabetes mellitus (175.0 $\pm 155.4 \mathrm{mg}$ and $137.5 \pm 75 \mathrm{mg}$, respectively) followed by unspecified rheumatism $(135.3 \pm 170.6 \mathrm{mg})$ and the lowest was for unspecified osteoarthritis $(62.5 \pm 28.8)$. There were no statistically significant differences in the daily dose in tapentadol according to diagnosis $(\mathrm{p}=0.094)$.

In oxycodone/naloxone the highest daily dose was for unspecified rheumatism $(33.3 \pm 26.6 \mathrm{mg})$ and the lowest for unspecified osteoarthritis $(17.5 \pm 12.8 \quad \mathrm{mg})$. Nevertheless, there were statistically significant differences in the daily dose of oxycodone with respect to the diagnoses $(p=0.049)$. The significant differences $(p=$ 0.032) were found between the daily dose of osteoarthritis $(21.0 \pm 16.4 \mathrm{mg})$ and neoplasic processes $(33.2 \pm 29.3 \mathrm{mg})$, after applying Bonferroni test.

\section{Diagnoses vs Treatment Duration}

In the case of tapentadol, the highest treatment duration was in the incorrect indication of depressive disorder (365.5 \pm 301.7 days) followed by osseous stenosis (242.8 \pm 223.1 days) and unspecified rheumatism (242.2 \pm 316.5 days) and the shortest was for non-associated diagnoses (94.8 \pm 66.8 days). There were statistically significant differences in the duration of tapentadol treatment concerning the diagnoses $(p<0.005)$. Concretely, the significant differences were found concerning neoplasic processes (122.3 \pm 102.2 days) and neuralgia (208.3 \pm 225.7 days), and neoplasic processes and other diagnosis (239.2 \pm 279.7 days), neuralgia (208.3 \pm 225.7 days) and not associated diagnosis (94.8 \pm 66.8 days), osteoarthritis (198.4 \pm 199.5 days) and not associated diagnosis (94.8 \pm 66.8 days), fibromyalgia (229 \pm 278.1 days) and not associated 
Table I Distribution of Patients Taking Tapentadol and Oxycodone/Naloxone and Their Diagnoses

\begin{tabular}{|c|c|c|c|c|c|}
\hline \multirow[t]{2}{*}{ Diagnosis } & \multirow[t]{2}{*}{ ICD-I 0} & \multicolumn{2}{|c|}{ Tapentadol } & \multicolumn{2}{|c|}{ Oxycodone/Naloxone } \\
\hline & & $\mathbf{N}$ & $\%$ & $\mathbf{N}$ & $\%$ \\
\hline Neuralgia* & $* *$ & 776 & 42.2 & 335 & 34 \\
\hline Osteoarthritis & MI5, MI6, MI7, MI9, M48 & 265 & 14.4 & 134 & 13.6 \\
\hline Neoplasic processes & $* * *$ & 97 & 5.3 & 50 & 5.1 \\
\hline Fracture and osteoporosis & $* * * *$ & 94 & 5.1 & 78 & 7.9 \\
\hline Fibromyalgia & M79.7 & 86 & 4.7 & 48 & 4.9 \\
\hline Joint pain & M25.5 & 53 & 2.8 & 26 & 2.6 \\
\hline Chronic pain & R52.2 & 48 & 2.6 & 50 & 5.1 \\
\hline Osseous stenosis & M99.3 & 36 & 2 & 13 & 1.3 \\
\hline Unspecified rheumatism & M79.0 & 34 & 1.9 & 6 & 0.6 \\
\hline Unspecified Osteoarthritis & MI9.9 & 18 & 1 & 16 & 1.6 \\
\hline Algoneurodystrophy & M89.0 & 8 & 0.4 & 4 & 0.4 \\
\hline Paraplegia & G82 & 4 & 0.2 & - & - \\
\hline Depressive disorder & F33.2 & 4 & 0.2 & - & - \\
\hline Diabetes mellitus & EIO & 4 & 0.2 & - & - \\
\hline More than I diagnosis associated & & 144 & 7.8 & 122 & 12.4 \\
\hline Other diagnosis & & 93 & 5.1 & 64 & 6.5 \\
\hline Not associated diagnosis & & 76 & 4.1 & 39 & 4 \\
\hline
\end{tabular}

Notes: *Neuralgia, lumbago with sciatica, sciatica, spondylosis, dorsalgia, lumbalgia, intervertebral disc disorder. **D86.9, G35, G50.0, G53.0, G56.2, G56.4, G62.0, G62.9, G63.0, G63.2, MI7.9 M34, M35.3, M4I, M43.I, M45, M46.9, M47, M47.2, M47.8, M47.9, M48.0, M50.2, M50.9, M5I.0, M5I.I, M5I.2, M5I.9, M53.I, M54, M54.I, M54.2, M54.3, M54.4, M54.5, M54.8, M65.8, M70.6, M75, M75.0, M75.I, M75.8, M75.9, M76.6, M79.I, M79.2, M99.3, M99.5, TI4.0. *** C50.9, C79.5, C50, C34.9, C6I, C64, C18.9, C79.8, C16.9, C67.9, C7I.9, C72, C78.0, C80, C96.9, C0I, C06.9, C18.7, C25.9, C47.8, C53.9, C78.6, C8I, C90.0, C22. **** T08, M80.9, M8I, S32.0, M80, M8I.9, S22.0, S32.8, M48.4, M80.4, S12.9, S22.3, S32, S42.2, S42.3, S62.6, S82.2, S82.4.

diagnosis (94.8 \pm 66.8 days), more than one diagnosis associated (216.5 \pm 236.2 days) and not associated diagnosis (94.8 \pm 66.8 days), other diagnosis (239.2 \pm 279.7 days) and not associated diagnosis ( $94.8 \pm 66.8$ days), after applying Bonferroni test $(p=0.035, p=0.031, p=0.002, p=0.036$, $\mathrm{p}=0.013, \mathrm{p}=0.012, \mathrm{p}=0.031$, respectively).

The highest duration of treatment with oxycodone/naloxone was in patients with more than one diagnosis $(315.5$ \pm 371.8 days) and the shortest for algoneurodystrophy (90.0 \pm 0 days). There were statistically significant differences in the duration of oxycodone/naloxone treatment about the diagnoses $(\mathrm{p}<0.005)$. In this case, the significant differences were found about neoplasic processes (135.9 \pm 76 days) and more than one diagnosis associated (315.5 \pm 371.8 days), not associated diagnosis ( $92.1 \pm 61.1$ days) and more than one diagnosis associated (315.5 \pm 371.8 days), fibromyalgia (311.4 \pm 379.5 days) and more than one diagnosis associated (315.5 \pm 371.8 days), after applying Bonferroni test $(\mathrm{p}=0.013$, $\mathrm{p}=0.001, \mathrm{p}=0.027$, respectively).

\section{Discussion}

This is a drug utilization study focus on a population with active prescription of tapentadol or the combination oxycodone-naloxone in a specific region of a country, and its results do not necessarily be directly applicable to others. However, it provides information about prescription patterns such as dose prescribed and the extent of use by higher-risk populations and their results could be representative of other countries.

\section{Description of the Population}

Tapentadol was used approximately 2 times more than oxycodone/naloxone at the cutoff date. This could be explained by the fact that tapentadol extended release is related with substantially lesser incidences of gastrointestinal side effects than oxycodone/naloxone combination. ${ }^{12,19-21}$

In addition, all patients used prolonged-release tablets also in tapentadol (the only one that has immediate-release tablets), which are indicated to control severe chronic pain and not acute pain. ${ }^{15,16,22}$ This also indicates that the six patients who were taking the two medications simultaneously were a duplication that would have to be intervened by de-prescribing one of the two opioids, since they did not intend to treat breakthrough pain in which immediate-release analgesics are used as a "rescue" medication. $^{15,16}$ 
Table 2 Other Diagnoses Associated with Tapentadol Prescription

\begin{tabular}{|c|c|c|c|}
\hline Other Diagnoses Tapentadol & ICD-IO & $\mathbf{N}$ & $\%$ \\
\hline Other disorders of the peripheral nervous system & G64 & 4 & 0.22 \\
\hline Peripheral vascular disease, unspecified & 173.9 & 4 & 0.22 \\
\hline Injury of unspecific body region & TI4 & 4 & 0.22 \\
\hline Lateral epicondylitis & M77.I & 3 & 0.16 \\
\hline Enthesopathy, unspecified & M77.9 & 3 & 0.16 \\
\hline Herpes zoster without complication & B02.9 & 2 & 0.11 \\
\hline Hypothyroidism, unspecified & E03.9 & 2 & 0.11 \\
\hline Post viral fatigue syndrome & G93.3 & 2 & 0.11 \\
\hline Stroke, not specified as hemorrhage or infarction & 164 & 2 & 0.11 \\
\hline Systemic lupus erythematosus, unspecified & M32.9 & 2 & 0.11 \\
\hline Cervicobrachial syndrome & M53.I & 2 & 0.11 \\
\hline Rotator cuff syndrome & M75.I & 2 & 0.11 \\
\hline Another osteonecrosis & M87.8 & 2 & 0.11 \\
\hline Endometriosis, not specified & N80.9 & 2 & 0.11 \\
\hline Pelvic and perineal pain & RI0.2 & 2 & 0.11 \\
\hline Abdominalgia & $\mathrm{RI} 0.4$ & 2 & 0.11 \\
\hline Paresthesia of skin & $\mathrm{R} 20.2$ & 2 & 0.11 \\
\hline Other and unspecified abnormalities of gait and mobility & R26.8 & 2 & 0.11 \\
\hline Tear of meniscus, current injury & S83.2 & 2 & 0.11 \\
\hline Problems related to living in residential institutions & Z59.3 & 2 & 0.11 \\
\hline Hemorrhagic thrombocythemia (essential) & D47.3 & 1 & 0.05 \\
\hline Iron deficiency anemia, unspecified & D50.9 & 1 & 0.05 \\
\hline Sarcoidosis, unspecified & D86.9 & 1 & 0.05 \\
\hline Parkinson's disease & $\mathrm{G} 20$ & 1 & 0.05 \\
\hline Other chorea & G25.5 & 1 & 0.05 \\
\hline Other specified extrapyramidal and movement disorders & $\mathrm{G} 25.8$ & 1 & 0.05 \\
\hline Lesion of ulnar nerve, unspecified side & G56.2 & 1 & 0.05 \\
\hline Causalgia & G56.4 & 1 & 0.05 \\
\hline Other diseases of spinal cord & G95 & $\mathrm{I}$ & 0.05 \\
\hline Other peripheral vertigo & $\mathrm{H} 8 \mathrm{I} .3$ & 1 & 0.05 \\
\hline Essential hypertension (primary) & 110 & I & 0.05 \\
\hline Atrial fibrillation and atrial flutter, unspecified & 148 & 1 & 0.05 \\
\hline Phlebitis and thrombophlebitis of unspecified site & 180.9 & 1 & 0.05 \\
\hline Unspecified acute lower respiratory infection & $\mathrm{J} 22$ & 1 & 0.05 \\
\hline Anal fistula & $\mathrm{K} 60.3$ & 1 & 0.05 \\
\hline Cholangitis & K83.0 & 1 & 0.05 \\
\hline Other chronic pancreatitis & K86.I & 1 & 0.05 \\
\hline Gastrointestinal hemorrhage, unspecified & K92.2 & 1 & 0.05 \\
\hline Decubitus ulcer and pressure area & L89 & 1 & 0.05 \\
\hline Lupus erythematosus & L93 & 1 & 0.05 \\
\hline Psoriatic and enteropathy arthropathies & M07 & 1 & 0.05 \\
\hline Gout, unspecified & MI0.9 & 1 & 0.05 \\
\hline Sicca syndrome (Sjogren) & M35.0 & 1 & 0.05 \\
\hline Spinal instabilities & M53.2 & 1 & 0.05 \\
\hline Contracture of muscle & M62.4 & 1 & 0.05 \\
\hline Other synovitis and tenosynovitis & M65.8 & 1 & 0.05 \\
\hline Trochanteric bursitis & M70.6 & 1 & 0.05 \\
\hline Palmar fascial fibromatosis (Dupuytren) & M72.0 & 1 & 0.05 \\
\hline Plantar fascial fibromatosis & M72.2 & 1 & 0.05 \\
\hline Achilles tendinitis & M76.6 & 1 & 0.05 \\
\hline Other specified osteochondropathies & M93.8 & 1 & 0.05 \\
\hline
\end{tabular}

(Continued) 
Table 2 (Continued).

\begin{tabular}{|c|c|c|c|}
\hline Other Diagnoses Tapentadol & ICD-IO & $\mathbf{N}$ & $\%$ \\
\hline Interstitial cystitis (chronic) & N30.I & I & 0.05 \\
\hline Urinary tract infection & N39.0 & I & 0.05 \\
\hline Other specific disorders of the male genital organs & N50.8 & I & 0.05 \\
\hline Congenital hiatus hernia & Q40.I & 1 & 0.05 \\
\hline Neurofibromatosis (nonmalignant) & Q85.0 & 1 & 0.05 \\
\hline Another chest pain & R07.3 & 1 & 0.05 \\
\hline Difficulty in walking, not elsewhere classified & $\mathrm{R} 26.2$ & I & 0.05 \\
\hline Ataxia, unspecified & R27.0 & 1 & 0.05 \\
\hline Unspecified urinary incontinence & R32 & I & 0.05 \\
\hline Multiple superficial injuries, unspecified & T00.9 & I & 0.05 \\
\hline Injury of muscles and tendons of unspecified body region & TI4.6 & I & 0.05 \\
\hline Crushing injury and traumatic amputation of unspecified body region & TI4.7 & I & 0.05 \\
\hline Complication of procedure, unspecified & $\mathrm{T} 81.9$ & 1 & 0.05 \\
\hline Follow-up care involving plastic surgery of lower extremity & Z42.4 & 1 & 0.05 \\
\hline
\end{tabular}

Table 3 Other Diagnoses Associated with Oxycodone/Naloxone Prescription

\begin{tabular}{|c|c|c|c|}
\hline Other Diagnoses Oxycodone/Naloxone & ICD-IO & $\mathbf{N}$ & $\%$ \\
\hline Peripheral vascular disease, unspecified & 173.9 & 4 & 0.41 \\
\hline Trochanteric bursitis & M70.6 & 3 & 0.30 \\
\hline Sacroiliitis, not elsewhere classified & M46.I & 3 & 0.30 \\
\hline Other disorders of the peripheral nervous system & G64 & 2 & 0.20 \\
\hline Arthropathic psoriasis & L40.5 & 2 & 0.20 \\
\hline Chondromalacia patellae & M22.4 & 2 & 0.20 \\
\hline Zoster without complications & B02.9 & 2 & 0.20 \\
\hline Chronic kidney disease, unspecified & NI8.9 & 2 & 0.20 \\
\hline Parkinson disease & G20 & 2 & 0.20 \\
\hline Diabetic polyneuropathy (el0-el4 + with common fourth character) & G63.2 & 2 & 0.20 \\
\hline Systemic involvement of connective tissue & M35.9 & I & 0.10 \\
\hline Other chondrocalcinosis & MII.2 & I & 0.10 \\
\hline Other congenital deformities of hip & Q65.8 & I & 0.10 \\
\hline Other specified urinary incontinence & N39.4 & I & 0.10 \\
\hline Osteonecrosis, unspecified & M87.8 & 1 & 0.10 \\
\hline Unstable angina & 120.0 & 1 & 0.10 \\
\hline Medical care, unspecified & Z51.9 & I & 0.10 \\
\hline Palliative care & Z5I.5 & I & 0.10 \\
\hline Calculus of kidney & N20.0 & I & 0.10 \\
\hline Headache & R5I & I & 0.10 \\
\hline Impacted cerumen & $\mathrm{H} 6 \mathrm{I} .2$ & I & 0.10 \\
\hline Nerve root and plexus compressions in other dorsopathies & G55.3 & I & 0.10 \\
\hline Diabetes mellitus type 2 without complications & EII.9 & 1 & 0.10 \\
\hline Discitis, unspecified & M46.4 & I & 0.10 \\
\hline Dyspnea & R06.0 & I & 0.10 \\
\hline Severe depressive episode without psychotic symptoms & $\mathrm{F} 32.2$ & I & 0.10 \\
\hline Hemiplegia, unspecified & G8I.9 & 1 & 0.10 \\
\hline Ankylosing hyperostosis & M48.I & I & 0.10 \\
\hline Lesion of ulnar nerve & G56.2 & I & 0.10 \\
\hline
\end{tabular}

(Continued) 
Table 3 (Continued).

\begin{tabular}{|c|c|c|c|}
\hline Other Diagnoses Oxycodone/Naloxone & ICD-I0 & $\mathbf{N}$ & $\%$ \\
\hline Superficial injury of unspecified body region & TI4.0 & I & 0.10 \\
\hline Systemic lupus erythematosus & M32 & I & 0.10 \\
\hline Hypertensive heart disease without heart failure & 111.9 & I & 0.10 \\
\hline Unspecified human immunodeficiency virus (HIV) disease & B24 & I & 0.10 \\
\hline Pulmonary heart disease, unspecified & 127.9 & I & 0.10 \\
\hline Neurofibromatosis (nonmalignant) & Q85.0 & I & 0.10 \\
\hline Persons encountering health services in other specified circumstances & Z76.8 & I & 0.10 \\
\hline Polyneuropathy, unspecified & G62.9 & I & 0.10 \\
\hline Unspecified problem related to medical facilities and other health care & Z75.9 & I & 0.10 \\
\hline Problems related to living in residential institution & Z59.3 & I & 0.10 \\
\hline Rectal prolapse & K62.3 & I & 0.10 \\
\hline Sequelae of poliomyelitis & B91 & I & 0.10 \\
\hline Impingement syndrome of shoulder & M75.4 & I & 0.10 \\
\hline Phantom limb syndrome with pain & G54.6 & I & 0.10 \\
\hline Carpal tunnel syndrome & G56.0 & I & 0.10 \\
\hline Nephrotic syndrome, unspecify & N04.9 & I & 0.10 \\
\hline Calcific tendinitis of shoulder & M75.3 & I & 0.10 \\
\hline Sacrococcygeal disorders, not elsewhere classified & M53.3 & I & 0.10 \\
\hline Crushing injury and traumatic amputation of unspecified body region & TI4.7 & I & 0.10 \\
\hline In growing nail & L60.0 & I & 0.10 \\
\hline Varicose veins of lower extremities with ulcer & 183.0 & I & 0.10 \\
\hline
\end{tabular}

Although the use of tapentadol or oxycodone/naloxone between sex was diverse, there was a higher percentage of women than men with active prescriptions of these drugs. This difference could be explained because the pain threshold in women and men is different. ${ }^{23-25}$

\section{Renal and Hepatic Function}

In the study, $1.5 \%$ of patients treated with tapentadol $(\mathrm{N}=$ 28 ) and $1.5 \%$ of patients treated with oxycodone/naloxone $(\mathrm{N}=15)$ had severe (GFR: $15-29 \mathrm{~mL} / \mathrm{min}$ ) chronic kidney disease (CKD). According to the SmPC, tapentadol has not been studied in controlled efficacy trials in patients with severe CKD; therefore, its use is not recommended in this population. ${ }^{15}$ Also, patients with CKD have shown higher plasma concentrations of oxycodone and naloxone. Thus, caution should be taken when using oxycodone/ naloxone medications in patients with mild CKD (GFR: $60-89 \mathrm{~mL} / \mathrm{min}$ ) and in the case of patients with severe CKD, strict medical surveillance is needed. ${ }^{16}$

As for liver function, around $4 \%$ of patients from each group (28 patients treated with tapentadol and 15 with oxycodone/naloxone) suffered from impaired liver function. The impairment of opioid metabolism increases in line with increased liver dysfunction, hence major changes in opioid metabolism have been detected mainly in patients suffering from severe liver diseases, ie, cirrhotic patients. Therefore, among opioids that could require a prolonged dose interval, or a dose reduction are tapentadol and oxycodone. ${ }^{26}$ According to the SmPC, tapentadol should be used with caution in patients with moderate hepatic impairment. In the case of severe hepatic impairment, no clinical studies have been found with tapentadol; therefore, its use is not recommended in this population. ${ }^{15}$ As for oxycodone/naloxone, clinical trials have shown that plasma concentrations of both oxycodone and naloxone are higher in patients with impaired liver function. This means that medicines containing oxycodone and naloxone as active ingredients are contraindicated in patients with moderate or severe liver failure. $^{16}$

Finally, although in general no dose adjustment was necessary in elderly patients in any of the treatments, considering the age profile of the population of the present study and that elderly patients are more likely to have kidney and liver dysfunction, caution must be exercised when choosing the dose, as recommended. 


\section{Treatment Duration}

Almost half of the patients, both in tapentadol (51.5\%) and oxycodone/naloxone (43.2\%), had durations of treatment between one and three months. However, almost the other half (45.3 and $48.6 \%$ in tapentadol and oxycodone/naloxone, respectively) had treatment durations ranging from more than 90 days to more than 2 years, despite the very limited evidence on the efficacy and safety of long-term opioid treatment. ${ }^{27,28}$

Often, the liability for chronic pain management and decision in starting an opioid therapy lies on the general practitioners and other non-specialist opioid prescribers, as emergency doctors. ${ }^{26}$ Insufficient training and information about opioid management protocols, time pressure to assess patients properly are some of the reasons that could explain the off-label prescription of opioids. ${ }^{26}$ A pain specialist or access to specialized and integrative care to re-evaluate the treatment might be needed in patients who had no improvement for the first three months. $^{7,9}$

\section{Prescribed Daily Dose}

In this study variable differences were found between the two drugs. Thus, in the case of tapentadol, no statistically significant differences were found in the prescribed daily dose as a function of age. However, an increase in daily doses is observed in older patients (age groups 81-90 and $>90$ years). Quite the opposite happened in the oxycodone/ naloxone combination, where there was a trend of decreasing daily dose values with increasing age that was statistically significative.

The general warning on the safety of patients based on the daily dose used, considering the majority age group found in the present study and the renal and liver functions of these patients, could be especially relevant in the case of tapentadol. Furthermore, only in the case of tapentadol, 3 patients were found who, although young, exceeded the authorized dose according to the SmPC. ${ }^{16}$ On the other hand, underdosed patients were found in both tapentadol and oxycodone/naloxone ( $7.2 \%$ and $18.2 \%$, respectively).

Therefore, some patients included in this study had improper dosages, so prescribed daily doses for these patients should be reviewed in the prescription program to prevent both overdosing and underdosing. According to European Pain Federation, the correct dose of an opioid is the lowest possible dose that achieves the desired outcome. ${ }^{9,26}$ The decision to modify opioid dosage must be made considering pain reassessment since increased risk of serious harms appears to be dose-dependent, ${ }^{27,28}$ patient adherence on treatment, and frequency of monitoring, among others.

Besides, additional evidence confirms an association between opioids and increased risk of serious harms that appears to be dose-dependent, ${ }^{27,28}$ they should only be introduced when strictly necessary and with due respect to a continuous risk-benefit analysis.

If we analyze the daily dose according to sex in both treatments, men took more doses than women. Although these differences were significant only in the case of oxycodone/naloxone, this is consistent with published data suggesting that elderly patients and females may suffer from bias in pain assessments or dosing ${ }^{23}$ this could be, as it was commented before because women had less intensity of pain than men. ${ }^{23-25}$ Results of a genome wide association study suggested that differences experienced by men and women in chronic pain are likely to have a genetic basis. ${ }^{29}$

By studying the daily dose depending on the duration of treatment, in both cases an increasing length of treatment increased the daily dose used, being significant, both positive correlations. The literature shows a strong relationship between initial exposure to opioids and the likelihood of long-term use and, therefore, an increase in tolerance. $^{30}$ Thus, the progression of long-term opioid use, should be prevented, in cases where it is not necessary, or it is clinically inadequate., ${ }^{9,26,31}$

\section{Drug Treatment Combination with Tapentadol and Oxycodone/Naloxone}

Tapentadol and oxycodone/naloxone followed a similar pattern related to concomitant medications. It is remarkable that more than $85 \%$ of patients were taking simultaneously so many pain medications, being some of the most used analgesics, antiepileptics, antidepressants, anxiolytics, selective serotonin reuptake inhibitor and sedatives. As it was mentioned before, polymedication is considered an important risk factor, because involves a major therapeutic complexity and a lower adherence to treatment, which negatively influences the achievement of expected clinical improvement. In addition, the increase in potential drug interactions and side effects, especially in the elderly due to the decrease in hepatic, renal and cardiac functions, should be noted. ${ }^{16}$ 


\section{Diagnoses}

The diagnoses for which tapentadol and oxycodone/naloxone are prescribed followed a similar pattern. Around $42 \%$ of tapentadol and around 34\% of oxycodone/naloxone prescriptions were for neuralgia, spondylosis, lumbago with sciatica or intervertebral disc disorders. The second common diagnoses in both drugs were related to osteoarthritis, which is the most usual form of joint disease and the main cause of pain and physical disability in the elderly. ${ }^{26}$ The third were related to fractures and osteoporosis.

Only around 5\% of diagnoses were neoplasms for the two drugs studied. Around 4\% of patients had not associated diagnosis, in those cases, the dose was lower than in the others, and length of treatment was 94 days.

At this point, it is important to highlight, that opioids should only be introduced when strictly necessary. Many patients may tolerate and respond to this treatment, and it should not be denied to them when deemed medically necessary by a responsible physician., ${ }^{9,26,31}$

Throughout the discussion, several interventions that would be necessary to improve the use of these drugs have already been indicated. Thanks to this study, inappropriate posology of tapentadol and oxycodone/naloxone has been detected and in September 2019 the recommended posology of both drugs has been added to the electronic primary care clinical station (ECAP). The ECAP prescription module proposes now the approved dosage regimen for each drug and the physician should review and modify the prescription if necessary. Furthermore, other interventions would be, for example, better practices in promotion of medicines and subsequent training to prescribers and other health professionals to raise awareness about opioids risk. ${ }^{26}$ Wong et ${ }^{32}$ al pointed out the implementation of interventions for emergency department utilizing patients with chronic noncancer pain could decrease the frequency of visits, care-associated costs, amount of opioid administration and prescription.

\section{Conclusions}

We found that the use of tapentadol and the combination oxycodone/naloxone in primary health care was characterized by female patients between 71 and 90 years of age and with mild or moderate decrease in renal function. Typical use was of one of these opioids at lower doses than men for an average of 31 to 90 days. Daily doses were higher in longer treatments, mainly of between one and two years of duration.
To conclude, the pattern of use and profile of patients with tapentadol and oxycodone/naloxone had more similarities than differences. The study suggested that prescribing practices and patient monitoring should be assessed regularly to ensure patient safety and effective management of pain.

\section{Patient and Public Involvement}

Patients and the public were not involved in the design or execution of this study.

\section{Data Sharing Statement}

Data used in this study are available from the corresponding author upon reasonable request.

\section{Ethics Approval}

Ethical approval was not required as it was made a secondary analysis of suitably anonymized data sets. It was not an experimental study and patients were not recruited.

\section{Author Contributions}

All authors made a significant contribution to the work reported, whether that is in the conception, study design, execution, acquisition of data, analysis and interpretation, or in all these areas; took part in drafting, revising or critically reviewing the article; gave final approval of the version to be published; have agreed on the journal to which the article has been submitted; and agree to be accountable for all aspects of the work.

\section{Funding}

This research did not receive any specific grant from funding agencies in the public, commercial, or not-forprofit sectors.

\section{Disclosure}

All the authors report no conflicts of interest for this work and have disclosed that they have no significant relationships with or financial interests in any commercial companies related to this study or article.

Montserrat Viñas-Bastart: No conflict; Míriam OmsArias: No conflict; Àfrica Pedraza-Gutiérrez: No conflict; Irene Lizano-Díez: No conflict; Eduardo L. Mariño: No conflict, Pilar Modamio: No conflict. 


\section{References}

1. Treede R-D, Rief W, Barke A, et al. Chronic pain as a symptom or a disease: the IASP classification of chronic pain for the International Classification of Diseases (ICD-11). Pain. 2019;160(1):19-27. doi:10.1097/j.pain.0000000000001384

2. Goldberg DS, McGee SJ. Pain as a global public health priority. $B M C$ Public Health. 2011;11:770.

3. International Association for the Study of Pain (IASP). European Federation of IASP Chapters. Right to pain relief. 4A. Unrelieved pain is a major global healthcare problem; 2004. Available from: https://www.iasp-pain.org/GlobalYear/RighttoPainRelief. Accessed April 20, 2021.

4. Dahlhamer J, Lucas J, Zelaya C, et al. Prevalence of chronic pain and high impact chronic pain among adults - United States, 2016 MMWR. 2018;67(36):1001-1006.

5. Breivik H, Collett B, Ventafridda V, et al. Survey of chronic pain in Europe: prevalence, impact on daily life, and treatment. Eur J Pain. 2006;10(4):287-333.

6. Dueñas M, Salazar A, Ojeda B, et al. A nationwide study of chronic pain prevalence in the general Spanish population: identifying clinical subgroups through cluster analysis. Pain Med. 2015;16 (4):811-822.

7. Provenzano DA, Viscusi ER. Rethinking the role of opioids in the outpatient management of chronic nonmalignant pain. Curr Med Res Opin. 2014;30(10):2051-2062.

8. Els C, Jackson TD, Kunyk D, et al. Adverse events associated with medium- and long-term use of opioids for chronic non-cancer pain: an overview of Cochrane Reviews. Cochrane Database Syst Rev. 2017;10:CD012509.

9. Manchikanti L, Kaye AM, Knezevic NN, et al. Responsible, safe, and effective prescription of opioids for chronic non-cancer pain: American Society of Interventional Pain Physicians (ASIPP) guidelines. Pain Physician. 2017;20(2S):S3-S92.

10. Meske DS, Lawal OD, Elder H, et al. Efficacy of opioids versus placebo in chronic pain: a systematic review and meta-analysis of enriched enrolment randomized withdrawal trials. J Pain Res. 2018;11:923-934.

11. Faria J, Barbosa J, Moreira R, et al. Comparative pharmacology and toxicology of tramadol and tapentadol. Eur J Pain. 2018;22 (5):827-844.

12. Morgan CL, Jenkins-Jones S, Currie C, et al. Outcomes associated with treatment of chronic pain with tapentadol compared with morphine and oxycodone: a UK primary care observational study. $A d v$ Ther. 2019;36(6):1412-1425.

13. Vondrackova D, Leyendecker P, Meissner W, et al. Analgesic efficacy and safety of oxycodone in combination with naloxone as prolonged release tablets in patients with moderate to severe chronic pain. J Pain. 2008;9:1144-1154.

14. Huang L, Zhou JG, Zhang Y, et al. Opioid-induced constipation relief from fixed-ratio combination prolonged-release oxycodone/naloxone compared with oxycodone and morphine for chronic non-malignant pain: a systematic review and meta-analysis of randomized controlled trials. J Pain Symptom Manage. 2017;54(5):737-748.e3.

15. The Spanish Agency of Medicines and Medical Devices (AEMPS). Summary of Product Characteristics tapentadol (Palexia retard ${ }^{\circledR}$, Grünenthal pharma, S.A). Available from: https://cima.aemps.es/ cima/dochtml/ft/75917/FT_75917.html. Accessed May 20, 2019.

16. The Spanish Agency of Medicines and Medical Devices (AEMPS). Summary of Product Characteristics oxycodone/naloxone (Targin ${ }^{\circledR}$, Mundipharma pharmaceuticals, S.L.). Available from: https://cima.aemps. es/cima/dochtml/ft/71124/FT_71124.html. Accessed May 20, 2019.
17. Viñas-Bastart M, Oms-Arias M, Pedraza-Gutiérrez À, et al. Clinical use of pregabalin in general practice in Catalonia, Spain: a population-based cross-sectional study. Pain Med. 2018;19:1639-1649.

18. Government of Catalonia. Department of Health. Organization Chart: unit of coordination and strategy of the medicine; 2019. Available from: http://www14.gencat.cat/sacgencat/AppJava/organigrama.jsp? codi=10137\&jq=200001. Accessed December 20, 2020.

19. Afilalo M, Etropolski MS, Kuperwasser B, et al. Efficacy and safety of tapentadol extended release compared with oxycodone controlled release for the management of moderate to severe chronic pain related to osteoarthritis of the knee: a randomized, double-blind, placebo and active-controlled Phase III study. Clin Drug Investig. 2010;30:489-505.

20. Baron R, Jansen J-P, Binder A, et al. Tolerability, safety, and quality of life with tapentadol prolonged release (PR) compared with oxycodone/naloxone PR in patients with severe chronic low back pain with a neuropathic component: a randomized, controlled, open- label, phase 3b/4 trial. Pain Pract. 2016;16(5):600-619.

21. D'Amato T, Martorelli F, Fenocchio G, et al. Tapentadol vs oxycodone/naloxone in the management of pain after total hip arthroplasty in the fast track setting: an observational study. J Exp Orthop. 2019;6 (1):36.

22. Anekar AA, Cascella M. WHO Analgesic Ladder.In: StatPearls. Treasure Island (FL): StatPearls Publishing; 2021.

23. Zhang L, Losin EAR, Ashar YK, Koban L, Wager TD. Gender biases in estimation of others' pain. J Pain. 2021. doi:10.1016/j. jpain.2021.03.001

24. Bartley EJ, Fillingim RB. Sex differences in pain: a brief review of clinical and experimental findings. Br J Anesth. 2013;111(1):52-58.

25. Packiasabapathy S, Sadhasivam S. Gender, genetics, and analgesia: understanding the differences in response to pain relief. $J$ Pain Res. 2018;11:2729-2739.

26. O'Brien T, Christrup LL, Drewes AM, et al. European Pain Federation position paper on appropriate opioid use in chronic pain management. Eur J Pain. 2017;21(1):3-19.

27. Canadian Agency for Drugs and Technologies in Health. Long-acting opioids for chronic non-cancer pain: a review of the clinical efficacy and safety; 2015. Available from: https://cadth.ca/sites/default/files/ pdf/htis/aug-2015/RC0698\%20Opioids\%20Final.pdf. Accessed June 20, 2020.

28. Agency for Healthcare Research and Quality (AHRQ). Opioid Treatments for Chronic Pain. Comparative Effectiveness Review No. 229. AHRQ Publication No. 20-EHC011; 2020. Available from: https://effectivehealthcare.ahrq.gov/sites/default/files/pdf/ opioids-chronic-pain.pdf. Accessed June 20, 2021.

29. Johnston KJA, Ward J, Ray PR, et al. Sex-stratified genome-wide association study of multisite chronic pain in UK Biobank. PLoS Genet. 2021;17(4):e1009428.

30. Hadlandsmyth K, Mosher H, Lund BC. Associations between initial opioid exposure and the likelihood for long-term use. $J$ Am Pharm Assoc. 2019;59(1):17-22.

31. Bialas P, Maier C, Klose P, et al. Efficacy and harms of long-term opioid therapy in chronic non-cancer pain: systematic review and meta-analysis of open-label extension trials with a study duration $\geq 26$ weeks. Eur J Pain. 2020;24:265-278.

32. Wong CK, O'Rielly CM, Teitge BD, et al. The characteristics and effectiveness of interventions for frequent emergency department utilizing patients with chronic noncancer pain: a systematic review. Acad Emerg Med. 2020;27(8):742-752. 


\section{Publish your work in this journal}

Risk Management and Healthcare Policy is an international, peerreviewed, open access journal focusing on all aspects of public health, policy, and preventative measures to promote good health and improve morbidity and mortality in the population. The journal welcomes submitted papers covering original research, basic science, clinical \& epidemiological studies, reviews and evaluations, guidelines, expert opinion and commentary, case reports and extended reports. The manuscript management system is completely online and includes a very quick and fair peer-review system, which is all easy to use. Visit http://www.dovepress.com/testimonials.php to read real quotes from published authors. 